\title{
12
}

\section{FAKE NEWS ATTRIBUTIONS AS A SOURCE OF NONSPECIFIC STRUCTURE}

\author{
Jordan R. Axt, Mark J. Landau, and Aaron C. Kay
}

\section{Introduction}

Over the last several years, claims of "fake news" have become an integral aspect of understanding how individuals perceive the media and participate in the democratic process. Most commonly, the term "fake news" refers to false news stories created by people with the goal of spreading disinformation. In this case, "fake news" refers to knowingly communicating false information with the goal of misleading readers. One example of this form of fake news comes from Russian activists creating Facebook ads that showed doctored images of celebrities (falsely) claiming that Americans could vote from home (Wagner, 2017). Another example comes from the website 70news, whose now-deleted article (falsely) stating that Donald Trump had won the popular vote in the 2016 election briefly became one of the top results for Google News searches of "final election results" (Earl, 2016). In the years since this form of fake news became such a salient force in the 2016 US elections, there has been considerable research on why people believe in such disinformation (e.g., Allcott \& Gentzkow, 2017; Lazer et al., 2017; Pennycook, Cannon, \& Rand, 2018, Pennycook \& Rand, 2019a), who is most likely to do so (e.g., Anthony \& Moulding, 2018; Bronstein, Pennycook, Bear, Rand, \& Cannon, 2018), and how such beliefs can be reduced (e.g., Pennycook \& Rand, 2019b).

However, the term "fake news" has other meanings. In particular, the term "fake news" has also been used as a means of discrediting news stories from more reputable sources with which groups or individuals may disagree. For example, when the Kentucky newspaper The Courier Journal published a story noting that governor Matt Bevin had purchased his home for $45 \%$ of its market value from a political supporter (Schneider, 2018), Bevin tweeted that the story was "fake news" and the reporter who wrote it a "sick man" (Manchester, 2017). 
Here, Bevin is claiming that The Courier Journal was intentionally spreading false information in hopes of weakening his governorship, a claim that the reporter responsible for the story would presumably deny. These charges of "fake news" are deployed to undercut likely more legitimate news stories and to shed light on the possibility of a wider, coordinated effort among media members to spread false information with the goal of undermining certain political figures or causes.

These two uses of the term "fake news" have different origins, functions, and implications, so much so that in October 2018, the British government officially decided to no longer use the term "fake news" (Murphy, 2018), as the phrase had become conflated to mean a number of different processes, from genuine human error to intentional foreign interference in the democratic process. While much of the research on "fake news" has centered on political disinformation, we have begun to investigate the psychological function of this other form of "fake news", when individuals make fake news attributions in efforts of discrediting information from more reputable and legitimate sources.

In this chapter, we review how these attributions of fake news build upon prior psychological research on perceptions of bias in the media. Drawing off the tenets of compensatory control theory (CCT; Kay, Gaucher, Napier, Callan, \& Laurin, 2008), we then introduce the novel idea that such fake news attributions offer a source of "nonspecific structure" (Landau, Kay, \& Whitson, 2015) that allows individuals to preserve a structured (though nefarious) interpretation of reality. We then review both correlational and experimental data we have collected on this topic, before finally discussing some of the practical and theoretical implications for understanding fake news attributions as a source of structure, including possible interventions that may reduce the frequency of such claims.

\section{Prior research on biased media perceptions}

Biases in perceptions of the media have been the focus of much prior work in psychological research. For instance, while the primary findings of the classical "They saw a game" study (Hastorf \& Cantril, 1954) focuses on the biased perceptions of the Dartmouth and Princeton students, the authors open the work by illustrating how such biases also colored the reporting from each school's student newspaper. After Princeton won the unusually rough football game against their Dartmouth rivals, a writer in the Daily Princetonian noted the physical play was clear evidence that the Dartmouth players were "deliberately" attempting to hurt members of the Princeton team. Conversely, a writer in the Dartmouth argued that the Princeton coach had "purposely" instructed his own players to injure their opponents. Comparing across the two reports, it's clear how readers can form the belief that journalists themselves may be a source of bias; surely, many Dartmouth students reading the accounts of the game provided by the Princeton media (or vice versa) would come to the conclusion that the supposedly objective journalists were deliberately misrepresenting the "actual" events that occurred 
in the game. This suspicion of biases in the media could then generalize such that all stories, no matter their source, have at least the potential to be tainted by journalists' partisan motives.

Similar biases in perceptions of the media were later more fully explored in the "hostile media phenomenon" (Vallone, Ross, \& Lepper, 1985). In this work, researchers presented coverage of a prominent international event (the 1982 Beirut massacre) to participants who were either pro-Israeli or pro-Arab. All participants reported their perceptions of the objectivity and fairness of the media team responsible for the coverage. Results revealed that the pro-Israeli and pro-Arab participants saw the media coverage as equally biased against their own side. For instance, when using a $1=$ Biased against Israel to $9=$ Biased in favor of Israel response scale, pro-Israeli students saw the clip as opposing Israeli sentiment on average $(M=2.9)$ while pro-Arab students saw the same clip as supporting Israeli positions on average $(M=6.7)$. Moreover, participants higher in self-rated knowledge of the topic had stronger beliefs that the media were biased rather than objective.

These results shed light on several notable aspects of how individuals perceive the media. For one, participants consistently viewed the news media as opposing versus supporting their existing viewpoints, regardless of what their actual views were. This outcome is somewhat surprising, given various other self-serving biases in the way that people perceive and remember information; for instance, while people are more likely to forget negative information in memory (e.g., Zhang, Pan, Li, \& Guo, 2018) or have a widespread need to prioritize self-enhancing information (e.g., Gaertner, Sedikides, \& Cai, 2012; Seih, Buhrmester, Lin, Huang, \& Swann, 2013), similar processes did not occur in perceptions of the news media. Rather than view the media as a way of affirming their opinions, people appeared to be motivated to accentuate those aspects of the media that were inconsistent with their worldview.

In addition, the fact that greater self-rated knowledge of the topic was associated with larger perceptions of a biased media illustrates how greater investment in a cause or issue is not associated with stronger motivation to settle on an objective truth but rather a stronger motivation to discredit potentially conflicting information As a result, for many beliefs and perhaps especially for political beliefs, even well-informed people do not view the news media as a means of arriving at an unbiased perspective but rather as a source of bias that needs to be discounted. Indeed, this widespread distrust in the media may partly explain the rising polarization in political discourse (Iyengar \& Hahn, 2009). As people view the media more suspiciously, they may engage the media primarily as a means of supporting existing ideologies rather as a method for arriving at accurate perceptions of the world. To remain relevant, media organizations are increasingly pressured to cater to their viewers' ideologies, resulting in increased polarization across the media landscape.

This hostile media effect, in which members of opposing viewpoints view the same material as equally biased, is not lost on many journalists themselves. 
Indeed, to many public figures, perceptions of their supposed biases are so widespread that the best they hope for is to be seen as equally biased rather than unbiased. For instance, James Comey, the former director of the FBI turned political commentator and author, took pride in noting how another commenter called him a clear "political hack", but simply could not figure out which political party Comey was biased toward (Comey, 2018). Likewise, sports broadcasters Joe Buck and Bob Costas have each said they take solace in knowing that they will inevitably be labeled as biased by fanbases of both teams when calling the World Series (Sandomir, 2009).

However, although there is a long line of work on perceptions of bias in the media, it is a much more recent phenomenon for these biases to evolve into claims of "fake news", which carry the specific accusation that journalists are not merely selectively reporting certain facts but rather knowingly spreading false information to advance a particular viewpoint. This specific attribution of intentional deception on behalf of the news media carries its own consequences for how individuals perceive both the news media and the social world more generally.

\section{"Fake news": accidental or intentional?}

Much of the prior work on perceptions of the news media finds that many people see the media as a source of bias, particularly in the form of biases that oppose or downplay the causes individual readers support. However, claims of "fake news" go a step further in arguing that the news media are not merely biased (i.e., selectively reporting certain facts) but wrong (i.e., reporting information that is factually incorrect). In these cases, reporters can arrive at presenting incorrect information due to relatively unintentional (e.g., publishing an incorrect story after failing to double-check a timeline offered by a source) or intentional reasons (e.g., attempting to intentionally deceive readers in hopes of spreading a certain political viewpoint or ideology).

In one sense, these two competing attributions (i.e., incorrect news reports arriving from honest mistakes or from intentional deception) serve the same function in that they allow individuals the ability to discredit information that is inconsistent with one's worldview. As a result, such claims of "fake news" may be viewed as another form of motivated reasoning (Kunda, 1990), a process in which people work to discredit information that is threatening to one's worldview. However, these two forms of attributions carry strongly different implications for how one's social reality operates. Claiming instances of "fake news" arise from incompetence and honest mistakes is one means of discrediting them, but carries a perspective that the social world is random and lacks order. A world where journalists routinely spread false information due to simple negligence is one where serious mistakes occur that are largely impossible to predict. On the other hand, attributions that "fake news" occurs because of intentional deception provides an ordered but malicious world, where known actors behave in 
ways that can be predicted and understood. These attributions of fake news due to willful deception are likely to be especially appealing for understanding the news media, which can be conceptualized as a large group of coordinating agents working with shared goals to undermine the same, repeated targets.

Attributions of fake news due to deception (rather than honest mistakes) is a clear option for individuals seeking to both discredit news sources with which they disagree and preserve a conception of the world as an orderly place. This strategy then aligns with prior work arguing that environmental threats to feelings of personal control create greater individual preferences for well-structured explanations of reality (i.e., through nonspecific structure; Landau et al., 2015). When experiencing threats to personal control, many individuals may then prioritize a worldview that is high in structure, even if that same worldview implies a reality where other, nefarious actors continually work to oppose one's own interests. Parallel effects have emerged in prior work using various forms of threats to control. In one study, threats to personal control (such as through reading about the risks posed by climate change) resulted in greater endorsement of the notion that large companies were working to willfully destroy the environment (Rothschild, Landau, Sullivan, \& Keefer, 2012). Similarly, participants who were shown a list of threats over which they had very little control (e.g., exposure to various diseases) were more likely to think that political opponents were engaging in intentional, unethical behavior (e.g., through voter suppression) than participants whose feelings of control had not been threatened (Sullivan, Landau, \& Rothschild, 2010).

In both studies, individuals experiencing lower feelings of personal control were attempting to restore that control by promoting worldviews that were simultaneously more predictable. Prior work then suggests that one effective means of retaining a perception of structure is to see the world as the result of intentional actions rather than random, impersonal forces. Notably, this strategy holds for both positive and negative events. For example, nice weather on one's wedding day may be more likely to be attributed to a benevolent deity than to random luck. However, this work focuses primarily on negative events because we are interested in how people interpret undesired information in the political realm (i.e., negative news stories about preferred political figures). In these instances, people may seek to explain negative events not by random chance but through the malevolent intentions of others.

In the case of "fake news" attributions, survey data strongly suggest that many people believe journalists are spreading false news stories intentionally more so than unintentionally. Although it may be unsettling to believe that we are consistently exposed to reports that have been willfully fabricated, this perspective is quite common among Americans. In one recent survey, 53\% of Democrats, $79 \%$ of Independents, and $92 \%$ of Republicans reported believing that traditional news sources report news that they know to be "fake, false, or purposely misleading" (Fischer, 2018). Mirroring much of the prior work on threats to control, there is a widespread notion that instances of "fake news" are the result 
of intentional, coordinated efforts made by specific actors. In our work, we explore the individual and environmental factors that make such attributions of fake news as knowing deception psychologically appealing.

\section{Personal need for structure and fake news attributions}

One means for studying the relation between fake news attributions and need for structure can come from examining whether individual differences in need for structure, or manipulations that experimentally prompt a greater need for structure, are associated with greater willingness to attribute contested news stories as being a result of intentional deception compared to simple error. In particular, we believe that fake news attributions as being due to intentional deception should be associated with differences in the construct of Personal Need for Structure (PNS), which assesses variation in desire for a predictable and well-ordered world (Thompson, Naccarato, Parker, \& Moskowitz, 2001). Prior work on PNS has shown that the construct shows divergent validity from possibly related constructs like authoritarianism, uncertainty orientation, and psychological rigidity (Neuberg \& Newsom, 1993).

Much of the earliest work on PNS focused on relatively lower-level questions concerning how PNS was related to more basic social cognitive processes. For instance, individuals higher in PNS showed less complexity when asked to develop taxonomies for both non-social (e.g., colors) and social (e.g., descriptors of elderly people) stimuli, and exhibited greater reliance on gender stereotypes in an impression formation task (Neuberg \& Newsom, 1993). However, more recent work has shifted toward understanding the construct as a motivated phenomenon, meaning that individuals higher in PNS see a structured world not merely as a personal preference but as a source of meaning. From this perspective, PNS is not simply a cognitive style or an impartial tendency to think in simple, clear-cut ways. Rather, it describes individual differences in how much structure people desire in the world. This motivational perspective leads to a testable hypothesis: when individuals high in PNS encounter situations that threaten structure - such as complexity, inconsistency, or ambiguity - they will respond with exaggerated cognitive efforts to restore structure. We would not expect this compensatory response to structure threats if PNS were a "cold", unmotivated, cognitive style.

For instance, only individuals high in PNS reported greater meaning in life following a mortality threat, and parallel associations with meaning in life emerged among people high in both PNS and death-thought accessibility (Vess, Routledge, Landau, \& Arndt, 2009). In addition, only individuals high in PNS showed greater need to prioritize tradition in response to a terrorism-related threat (Routledge, Juhl, \& Vess, 2010). Finally, people high in PNS show lower levels of death-related anxiety after experiencing a mortality salience threat (Routledge, Juhl, \& Vess, 2013). In total, these more recent findings suggest that PNS is a partly motivated phenomenon; people naturally high in PNS (or 
induced to be so) do not simply prefer a more structured world but will rather use this preference for a structured world as a source of meaning (Swanson \& Landau, in press).

Drawing from this prior research, we developed several hypotheses concerning the relation between PNS and attributions of fake news as intentional deception. First, at a correlational level, PNS should be associated with belief that "fake news" (i.e., contested news stories) is more a result of willful deception on behalf of journalists than a series of honest but harmful mistakes. Second, this association between PNS and fake news attributions as a result of willful deception should exist for both ideologically consistent news (i.e., when individuals read stories that paint disliked political figured in a negative light) and ideologically inconsistent news (i.e., when individuals read stories that paint preferred political figures in a negative light). In other words, since belief that the news media is engaging in intentional deception is related to a larger desire to see the world as an ordered place, the effect should be seen both when news is and is not aligned with one's own political ideology. Such an analysis can then rule out attributions of intentional deception as simply being a form of in-group favoritism (i.e., when negative stories about candidates I like are retracted, it shows intentional bias, but when negative stories about candidates I dislike are retracted, it's just an honest mistake). Rather, attributions of intentional deception may better reflect a desire to retain a perception of structure.

Finally, to provide causal evidence on the connection between PNS and attributions of fake news, individuals randomly assigned to experience a threat to their feelings of personal control should then show a greater tendency to attribute errors in news reporting to intentional deception relative to simple mistakes caused by incompetence. We believe that such work has the potential to advance our understanding of the psychological processes behind the growing appeal of claiming "fake news".

\section{Studying fake news attributions}

One unavoidable challenge in studying attributions of fake news is the ultimately subjective nature of belief. To many, there is no difference between Russian instigators knowingly spreading false information - like articles claiming it is possible to vote from home or that Donald Trump had won the popular vote - and contested news stories from more established organizations, such as the report in The Courier Journal over the suspiciously low price Kentucky Governor Matt Bevin paid for his home. Similar accusations of fake news have followed some of the most established names in media, such as The New York Times, The Washington Post, and CNN. However, perceived legitimacy alone is not enough to convince skeptical readers that certain news items do not represent the willful spread of false information.

To avoid this issue, we believe it is productive to focus on cases where news organizations had to correct or retract stories. These retractions and corrections 
then provide a clear instance where reporters had made incorrect statements, which then forces readers into evaluating why such errors occurred - either as a result of honest mistakes or intentional misleading. For instance, in May of 2017, Fox News published an online article about the 2016 murder of Seth Rich (Grynbaum, 2018), a former employee of the Democratic National Committee (DNC). Among other details, the article speculated that Rich's death was somehow connected to the leak of emails from prominent DNC officials like John Podesta. In particular, the article implied that Rich may have been murdered by people working on behalf of the DNC as a form of payback for his possible role in leaking the sensitive emails.

Soon after the article appeared, several news organizations attacked Fox News for publishing the piece (e.g., Pilkington, 2017). These criticisms highlighted the distinct lack of hard evidence connecting anyone associated with the DNC to Rich's murder. Eventually, Fox News retracted the article and removed the content from their website because it did not meet the "high degree of editorial scrutiny" the site requires (Statement on coverage of Seth Rich, 2017). To Fox News defenders, the retracted story was only the result of an honest but harmful reporting error that occurred as a result of the natural reporting process, for example from failing to confirm accounts provided by anonymous sources. To others, the story was an example of a biased news organizations knowingly spreading false information in the hopes of furthering a specific political cause, such as painting the DNC in a negative light. The public was faced with the same problem: was the retracted report an instance where journalists made natural errors in the reporting process, or had Fox News simply been caught in a larger effort to intentionally deceive their audience? The Seth Rich story, and other retracted reports, force audience members to choose between a less harmful but random explanation based on honest mistakes versus a more malicious but structured explanation of coordinated deception.

In our initial studies on this topic (Axt, Landau, \& Kay, in press), we presented participants with descriptions of news stories that were retracted or corrected. For one study, participants only saw ideologically consistent news stories presented across multiple vignettes, which largely entailed retracted stories that depicted members of one's own political party in a negative light (e.g., Democratic participants read about the Fox News Seth Rich story, while Republican participants read about the retracted ABC News story that Michael Flynn was prepared to testify that Donald Trump had instructed him to collude with Russian officials to influence the 2016 presidential election). After reading each vignette, participants responded to a number of items that assessed the degree to which they believed the retracted story was either the result of honest errors in reporting versus a willful desire to spread knowingly false information. For instance, participants reported whether they believed it was more likely that the story's error was due to either a lack of attention or an intentional attack on behalf of the journalist. Responses were made on a six-point Likert scale, so 
participants could indicate a degree of confidence in their responses ("Extremely more likely to be an honest mistake", "Moderately more likely to be an honest mistake", etc.).

Across items, we then developed an internally reliable measure of the degree to which participants thought retracted news stories were a result of willful deception from the news media. We used this measure and examined the degree to which beliefs that erroneous news was due to willful deceptions was correlated with, and caused by, personal need for structure.

At a descriptive level, results were compatible with the previously mentioned survey finding that many Democrats and Republicans believe traditional the news media are knowingly spreading false information in hopes of furthering their own political agenda. For instance, in our first study, 72.7\% of Democrats believed that the Seth Rich story was due to active deception, and $84.9 \%$ believed the same to be true over Breitbart's retracted "Pizzagate" story concerning a possible sex-trafficking ring involving several prominent Democrats. Among Republicans, 53.5\% believed the ABC News story over Michael Flynn was an instance of journalists engaging in intentional deception, and 55.4\% provided the same explanation for a retracted "MSNBC" story alleging that Wikileaks had offered prominent Republican officials special access to DNC emails that would later be posted online. While Democrats appeared to have higher rates of attributions for intentional deception, the differences in study materials makes it difficult to compare rates between Democratic and Republican participants. Finally, though Independents were not included in primary analyses, their results also revealed that perceptions of deception were not limited to partisans; in the same study, $58.3 \%$ of Independents believed the Seth Rich Fox News story to be an act of intentional deception, and $40.0 \%$ thought the same over the Michael Flynn ABC News story.

Most importantly, across all studies, we observed a consistent, positive relationship between measured PNS (Thompson et al., 2001; example items include: "I become uncomfortable when the rules in a situation are not clear", and "I enjoy having a clear and structured mode of life") and a greater belief that the news media were actively trying to deceive their audience. In later studies, we found that this positive relationship persisted both when people learned about erroneous news reports that conflicted with and supported their political beliefs, and also persisted when individual differences in strength of political orientation was controlled for. These findings suggest that the association between PNS and attributions of intention deception reflect more than just a desire to enhance one's own political in-group or other forms of ideological bias; rather, PNS predicted attributions of intentional deception in news stories that negatively depicted both members of one's own or another political party.

We also sought to provide causal evidence on the influence of PNS on fake news attributions by employing an experimental design. Extant research finds that the most effective manipulations on feelings of structure come from threats 
to personal control (see Landau et al., 2015). We randomly assigned participants to reflect about aspects of their lives that were either relatively controllable versus uncontrollable (see Kay et al., 2008 for prior uses of this manipulation). Results found that those participants asked to reflect upon the uncontrollable aspects of life reported greater belief that news errors were the result of intentional deception versus honest mistakes. We also observed that responding to control threats via increased attributions of bias in news reporting helps buffer feelings that the world is structured.

In sum, then, our work highlights both a correlational and causal relationship between PNS and belief that the media are engaging in intentional deception through "fake news" stories. Across studies, this project illustrates one of the potential functions of fake news and provides groundwork for more general considerations into how claims of fake news can be best understood and even reduced.

\section{Technological progress and lessening the influence of fake news}

We believe our work establishes a connection between PNS and attributions of deception in the news media (i.e., claims of "fake news"). While finding such an association is important, it naturally leads to more practical questions concerning how we may apply prior findings related to PNS to the issue of mitigating the problem of fake news. Fortunately, past work on the need for nonspecific structure suggests several ways that attributions of intentional deception in the news media could be mitigated. Perhaps the most straightforward implication comes from research on the benefits of affirming feelings of structure, which is similar to the manipulation we used of asking participants to reflect on a time in their lives where they experienced control. Just as depriving participants of feelings of structure leads to a greater need to attribute order to external systems (e.g., Kay, Shepherd, Blatz, Chua, \& Galinsky, 2010; Wang, Whitson, \& Menon, 2012), providing participants with feelings of control or structure lessens this need. For example, participants who wrote about a time in their lives when they had high levels of control later showed reduced perceptions of hierarchy in an ambiguous social interaction, and reported less preference for hierarchy (i.e., a system of structure and order) when evaluating various workplace options (Friesen, Kay, Eibach, \& Galinsky, 2014).

Drawing from this and our own experimental work, it's clear that affirmation of structure offers one viable means of reducing attributions of fake news; simply put, ascribing malevolent but predictable intent to journalists should be less appealing to those individuals who have higher feelings of personal control. Practical applications of such results may require some creativity; it is not immediately clear how control manipulations can be seamlessly incorporated into the ways in which people receive their news. One possibility comes from social media and new forms of communication. While social media may be the greatest source of fake news - one recent study found that $8.5 \%$ of Facebook users had 
shared at least one story that could be labeled as political disinformation (Guess, Nagler, \& Tucker, 2019) - it may also provide the largest opportunity for people to regain feelings of personal control. Interacting with known others, sharing feelings about one's life, or curating one's information stream (e.g., by removing or adding friends) may be some ways in which people can feel some sense of control over their lives, and these features are increasingly common on social media platforms.

One potential prediction from the current work is that participants instructed to engage with social media in a more directed, controlled way may in fact show a lesser need to attribute motives of intentional deception to the news media. That is, instructing people to be more thoughtful with the information they view on social media platforms could lead to greater perceptions of structure in the world. Moreover, the benefits of affirmation of structure will likely not be limited to attributions of fake news, as separate research suggests that increased feelings of control can reduce levels of anxiety (Tullett, Kay, \& Inzlicht, 2014) or facilitate goal pursuit (Kay, Laurin, Fitzsimons, \& Landau, 2014). Instilling feelings of control has the potential to lessen negative consequences beyond belief in fake news. At the same time, people may experience both beneficial and harmful consequences as social media platforms become more tailored to individual preferences; such changes may create perceptions of a more structured world while also reinforcing partisan bubbles and removing the opportunity to view information not already aligned with one's worldview.

Another possible source of restoring feelings of control may come not from changing individual levels of feelings of control but from altering perceptions of the news media itself. Distrust and misperceptions of journalism are widespread. For instance, a recent survey (Columbia Journalism Review, 2019) found that less than $25 \%$ of Democrats and $15 \%$ of Republicans report having "a great deal of confidence" in the news media. In fact, among other institutions such as congress, the military, and the supreme court, the media received the highest rate of responses of participants having "hardly any confidence at all". Much of this lack of trust in the news media may stem from false beliefs in how journalism operates. For instance, in that same survey, 60\% of respondents believed that journalists pay their sources, and a similar percentage believed that journalists write their articles before learning the facts.

Given the prevailing distrust of the news media and the misperceptions of how journalism operates, attributions of fake news may also be lessened by increasing the transparency of the journalism process. That is, one reason that people may feel free to attribute intentional deception to the news media is that they lack an understanding of the journalistic process, from confirming facts with multiple sources to editing and fact checking. It is plausible that a greater understanding of these processes (and the relatively small rate of errors they produce) could assuage readers' skepticism that the news media is little more than journalists trying to advance their own political agendas. Potentially small changes, such as listing fact checkers and editors in by-lines or putting in headlines the number 
of sources used to confirm a story, may increase trust in the media and in turn reduce the allure of ascribing intentional deception to journalists. Technological advances in how media is consumed may make more sophisticated changes possible as well; for example, online readers could be shown primary supporting documents when scrolling over relevant passages. These interventions may not change individual levels of PNS, but they may redirect the desire for structure to other sources (e.g., government or religion; Kay et al., 2008; Kay, Gaucher, McGregor, \& Nash, 2010) and thereby lessen the potential for structure to be restored through ascribing malevolent intent to journalists.

We anticipate several possibilities for future directions in this area of research. A clear application is in the 2020 US presidential election, where the issue of "fake news" will very likely be relevant again. For instance, the 2020 election opens possibilities for longitudinal data collection, where researchers could track individual changes in personal need for structure and how those changes translate into mistrust of the news media. Similarly, while our experimental evidence suggests that changes to one's sense of structure lead to greater desire to believe in intentional deception, a bi-directional relationship could still exist, where rising mistrust in the news media could lead to later changes in need for structure. Finally, we anticipate that this work may be applied to identifying people who may be most susceptible to claiming "fake news"; for instance, past work has found that individuals lower in social status (e.g., Fiori, Brown, Cortina, \& Antonucci, 2006) may have chronically lower levels of personal control, and as a result will find attributions of intentional deception by the news media particularly appealing.

\section{Conclusion}

The rise of labeling news stories, often from legitimate outlets, as "fake news" alleging that journalists are intentionally deceiving the public by spreading false information - poses a serious threat not only for trust in the media but in the democratic process more broadly. Drawing from prior research on compensatory control theory and the personal need for structure, we believe that many fake news attributions are appealing because they offer an avenue for individuals to find sources of nonspecific structure in their environment. A better understanding of the psychological processes that give rise to such claims of fake news will accelerate theoretical and practical progress on how claims of fake news can be understood and potentially reduced.

\section{References}

Allcott, H., \& Gentzkow, M. (2017). Social media and fake news in the 2016 election. Journal of Economic Perspectives, 31, 211-236.

Anthony, A., \& Moulding, R. (2018). Breaking the news: Belief in fake news and conspiracist beliefs. Australian Journal of Psychology. Advance online publication. https:// doi.org/10.1111/ajpy.12233 
Axt, J. R., Landau, M. J., \& Kay, A. C. (in press). The psychological appeal of fake news attributions. Psychological Science.

Bronstein, M. V., Pennycook, G., Bear, A., Rand, D. G., \& Cannon, T. D. (2019). Belief in fake news is associated with delusionality, dogmatism, religious fundamentalism, and reduced analytic thinking. Journal of Applied Research in Memory and Cognition. Advance online publication. https://doi.org/10.1016/j.jarmac.2018.09.005

Columbia Journalism Review. (2019). Poll: How does the public think journalism happens? Retrieved from www.cjr.org/

Comey, J. (2018, September 30). James Comey: The F.B.I can do this. Retrieved from www.nytimes.com/

Earl, J. (2016, November 14). Google's top search result for "final election numbers" leads to fake news site. Retrieved from www.cbsnews.com

Fiori, K. L., Brown, E. E., Cortina, K. S., \& Antonucci, T. C. (2006). Locus of control as a mediator of the relationship between religiosity and life satisfaction: Age, race, and gender differences. Mental Health, Religion and Culture, 9, 239-263.

Fischer, S. (2018, June 27). 92\% of Republicans think media intentionally reports fake news. Retrieved from www.axios.com/

Friesen, J. P., Kay, A. C., Eibach, R. P., \& Galinsky, A. D. (2014). Seeking structure in social organization: Compensatory control and the psychological advantages of hierarchy. Journal of Personality and Social Psychology, 106, 590-609.

Gaertner, L., Sedikides, C., \& Cai, H. (2012). Wanting to be great and better but not average: On the pancultural desire for self-enhancing and self-improving feedback. Journal of Cross-Cultural Psychology, 43, 521-526.

Grynbaum, M. M. (2018, March 13). Family of Seth Rich sues Fox News over retracted article. The New York Times. Retrieved from www.nytimes.com/2018/03/13/business/ fox-news-seth-rich-lawsuit.html

Guess, A., Nagler, J., \& Tucker, J. (2019). Less than you think: Prevalence and predictors of fake news dissemination on Facebook. Science Advances, 5, eaau4586.

Hastorf, A. H., \& Cantril, H. (1954). They saw a game: A case study. The Journal of Abnormal and Social Psychology, 49, 129-134.

Iyengar, S., \& Hahn, K. S. (2009). Red media, blue media: Evidence of ideological selectivity in media use. Journal of Communication, 59, 19-39.

Kay, A. C., Gaucher, D., McGregor, I., \& Nash, K. (2010). Religious belief as compensatory control. Personality and Social Psychology Review, 14, 37-48.

Kay, A. C., Gaucher, D., Napier, J. L., Callan, M. J., \& Laurin, K. (2008). God and the government: Testing a compensatory control mechanism for the support of external systems. Journal of Personality and Social Psychology, 95, 18-35.

Kay, A. C., Laurin, K., Fitzsimons, G. M., \& Landau, M. J. (2014). A functional basis for structure-seeking: Exposure to structure promotes willingness to engage in motivated action. Journal of Experimental Psychology: General, 143, 486-491.

Kay, A. C., Shepherd, S., Blatz, C. W., Chua, S. N., \& Galinsky, A. D. (2010). For God (or) country: The hydraulic relation between government instability and belief in religious sources of control. Journal of Personality and Social Psychology, 99, 725-739.

Kunda, Z. (1990). The case for motivated reasoning. Psychological Bulletin, 108, 480-498.

Landau, M. J., Kay, A. C., \& Whitson, J. A. (2015). Compensatory control and the appeal of a structured world. Psychological Bulletin, 141, 694-722.

Lazer, D., Baum, M., Grinberg, N., Friedland, L., Joseph, K., Hobbs, W., \& Mattsson, C. (2017). Combating fake news: An agenda for research and action. Retrieved from https:// shorensteincenter. org/combating-fake-news-agenda-for-research/ 
Manchester, J. (2017, May 28). Kentucky Governor calls reporter a “sick man”. Retrieved from https://thehill.com/homenews/news/335487-kentucky-governor-calls-reportera-sick-man

Murphy, M. (2018, October 23). Government bans phrase "fake news". Retrieved from www.telegraph.co.uk/

Neuberg, S. L., \& Newsom, J. T. (1993). Personal need for structure: Individual differences in the desire for simpler structure. Journal of Personality and Social Psychology, 65, 113-131.

Pennycook, G., Cannon, T. D., \& Rand, D. G. (2018). Prior exposure increases perceived accuracy of fake news. Journal of Experimental Psychology General, 147, 1865-1880.

Pennycook, G., \& Rand, D. G. (2019a). Lazy, not biased: Susceptibility to partisan fake news is better explained by lack of reasoning than by motivated reasoning. Cognition. Advance online publication. https://doi.org/10.1016/j.cognition.2018.06.011

Pennycook, G., \& Rand, D. G. (2019b). Fighting misinformation on social media using crowdsourced judgments of news source quality. Proceedings of the National Academy of Sciences, 201806781.

Pilkington, E. (2017, August 7). The strange case of Fox News, Trump and the death of young Democrat Seth Rich. Retrieved from www.theguardian.com/

Rothschild, Z. K., Landau, M. J., Sullivan, D., \& Keefer, L. A. (2012). A dual-motive model of scapegoating: Displacing blame to reduce guilt or increase control. Journal of Personality and Social Psychology, 102, 1148-1163.

Routledge, C., Juhl, J., \& Vess, M. (2010). Divergent reactions to the terror of terrorism: Personal need for structure moderates the effects of terrorism salience on worldviewrelated attitudinal rigidity. Basic and Applied Social Psychology, 32, 243-249.

Routledge, C., Juhl, J., \& Vess, M. (2013). Mortality salience increases death-anxiety for individuals low in personal need for structure. Motivation and Emotion, 37, 303-307.

Sandomir, R. (2009, November 2). Some fans see enemies behind every microphone. Retrieved from www.nytimes.com/

Schneider, G. (2018, April 27). Matt Bevin's Anchorage home now valued at almost twice what he paid in controversial deal. Retrieved from www.courier-journal.com/

Seih, Y. T., Buhrmester, M. D., Lin, Y. C., Huang, C. L., \& Swann, W. B., Jr. (2013). Do people want to be flattered or understood? The cross-cultural universality of selfverification. Journal of Experimental Social Psychology, 49, 169-172.

Statement on coverage of Seth Rich murder investigation. (2017, May 23). Retrieved from www.foxnews.com/

Sullivan, D., Landau, M. J., \& Rothschild, Z. K. (2010). An existential function of enemyship: Evidence that people attribute influence to personal and political enemies to compensate for threats to control. Journal of Personality and Social Psychology, 98, 434-449.

Swanson, T. J., \& Landau, M. J. (in press). Terror management motivation fuels structureseeking. In C. Routledge \& M. Vess (Eds.), The handbook of terror management theory. Elsevier.

Thompson, M. M., Naccarato, M. E., Parker, K. C., \& Moskowitz, G. B. (2001). The personal need for structure and personal fear of invalidity measures: Historical perspectives, current applications, and future directions. In G. B. Moskowitz (Ed.), Cognitive social psychology: The Princeton symposium on the legacy and future of social cognition (pp. 19-39). Mahwah, NJ: Erlbaum.

Tullett, A. M., Kay, A. C., \& Inzlicht, M. (2014). Randomness increases self-reported anxiety and neurophysiological correlates of performance monitoring. Social Cognitive and Affective Neuroscience, 10, 628-635. 
Vallone, R. P., Ross, L., \& Lepper, M. R. (1985). The hostile media phenomenon: Biased perception and perceptions of media bias in coverage of the Beirut massacre. Journal of Personality and Social Psychology, 49, 577-585.

Vess, M., Routledge, C., Landau, M. J., \& Arndt, J. (2009). The dynamics of death and meaning: The effects of death-relevant cognitions and personal need for structure on perceptions of meaning in life. Journal of Personality and Social Psychology, 97, 728-744.

Wagner, K. (2017, October 31). These are some of the tweets and Facebook ads Russia used to try and influence the 2016 presidential election. Retrieved from www.recode. net/

Wang, C. S., Whitson, J. A., \& Menon, T. (2012). Culture, control, and illusory pattern perception. Social Psychological and Personality Science, 3, 630-638.

Zhang, Y., Pan, Z., Li, K., \& Guo, Y. (2018). Self-serving bias in memories: Selectively forgetting the connection between negative information and the self. Experimental Psychology, 65, 236-244. 